\title{
ARTIGOS SOBRE COMUNICAÇÃO E MÍDIA DE FRONTEIRA NO BRASIL NOS EVENTOS NACIONAIS DA INTERCOM (2001-2015)
}

\author{
Papers about Brazilian Borders Communication and Media at the Intercom \\ National Events (2001-2015)
}

\author{
Artículos sobre Comunicación Y Medios de Frontera en Brasil en Los Eventos \\ Nacionales de la Intercom (2001-2015)
}

Beatriz Corrêa Pires Dornelles Pesquisadora, professora $\mathrm{Dr}^{\mathrm{a}}$. (PUCRS) biacpd@pucrs.br

Heleno Rocha Nazário Jornalista, Mestre em Comunicação Social (PUCRS) helenorochanazario@gmail.com

\begin{abstract}
Resumo
$\mathrm{O}$ artigo expõe levantamento de pesquisas sobre mídias e processos comunicacionais nas cidades de fronteira do Brasil com os países da América Latina. O trabalho envolveu consultas aos repositórios de anais dos eventos nacionais do Congresso Brasileiro de Ciências da Comunicação, promovido anualmente pela Sociedade Brasileira de Estudos Interdisciplinares da Comunicação (Intercom), a partir da 24ª edição, ocorrida em 2001, em Campo Grande, Mato Grosso do Sul, na UFMS, até a 38 a realizada em 2015. Os dados de interesse são os autores mais prolíficos sobre o tema, o suporte midiático ou processo comunicacional estudado, localização e se há ou não comparação entre meios fronteiriços. Destacam-se entre os resultados a prevalência de estudos sobre mídia nas fronteiras da Região Sul e predomínio de pesquisadoras na realização dos estudos.
\end{abstract}

Palavras-chave: Comunicação. Pesquisa. Mídia de Fronteira.

\begin{abstract}
This paper exposes a survey of investigations about media and communicational processes at Brazilian cities located at the country borders with other Latin-American countries. Research consisted of queries applied to the online repository of the Brazilian Congress of Communication Sciences, annual event promoted by the Brazilian Society for Interdisciplinary Communication Studies (Intercom), ranging from the 24th edition, occurred in 2001, at UFMS, Campo Grande, Mato Grosso do Sul, till the 38th, realized in 2015. Relevant data for this paper are about the most prolific authors about the topic, type of media or communicational process, location, and about the existence of comparative studies. The
\end{abstract}


results point to a prevalence of studies about the Brazilian South region border media and of female researchers on the subject.

Key words: Communication. Research. Border Media.

\section{Resumen}

El artículo muestra un análisis de investigaciones sobre los medios y procesos comunicacionales en las ciudades fronterizas de Brasil con otros países de Latinoamérica. El trabajo implicó consultar el repositorio online de anales de los eventos nacionales del Congreso Brasileño de Ciencias de la Comunicación, promovido anualmente por la Sociedad Brasileña de Estudios Interdisciplinarios de la Comunicación (Intercom), desde la $24^{\text {a }}$ edición, ocurrida em 2001, en Campo Grande, Mato Grosso do Sul, hacia la 38 a realizada en 2015. Los datos que interesan son los autores más prolíficos sobre el tema, el soporte mediático u proceso comunicacional estudiado, la localización y si había o no comparación entre medios fronterizos. De los resultados se destacan la prevalencia de estudios sobre medios en las áreas fronterizas de la región Sur del Brasil y el predominio de investigadoras en este tema.

Palabras clave: Comunicación. Investigación. Medios fronterizos.

\section{INTRODUÇÃO}

A extensão da linha de fronteira da República Federativa do Brasil com os demais países da América Latina é de $15.735 \mathrm{Km}$, correspondendo a 68\% dos limites territoriais do país. Adjunta a essa linha, existe a designação político-administrativa da faixa de fronteira, correspondente a uma faixa interna de $150 \mathrm{~km}$ de largura a partir das linhas divisórias terrestres, que abrange 588 municípios em três regiões do país, Norte, Centro Oeste e Sul, sendo esta última a mais densamente povoada. Esses dados dão conta do aspecto políticoadministrativo do território nacional no que se refere às suas bordas. Além de demandas de origem governamental, as populações fronteiriças são co-promotoras de fluxos culturais, econômicos e sociais, em interação com os seus centros de poder, com os povoamentos vizinhos e com a estrutura estatal firmada nos dois (ou mais) lados dos limites territoriais.

O desafio imposto pela polissemia da palavra "fronteira" e o forte interesse despertado pelos fenômenos ocorridos nas bordas do Brasil em pesquisadores de diversos quadrantes do saber científico faz perguntar o quanto está presente esta temática nos estudos comunicacionais brasileiros. É preciso levar em consideração os processos de povoação sob os domínios espanhol e português, com as consequências de diferenciação em termos de desenvolvimento no território; as heranças da Doutrina de Segurança Nacional, das quais as restrições impostas aos municípios contidos na faixa de fronteira são as mais notáveis; e as conexões entre a Comunicação e áreas como a História, a Antropologia, a Sociologia e a 
Geografia como interfaces necessárias para dar conta da complexidade da relação entre as mídias e os pontos fronteiriços no Brasil.

Este artigo apresenta levantamento sobre onde está e como é a produção científica comunicacional brasileira sobre a mídia de fronteira e os processos comunicacionais que ali tem lugar, ou que são vistos a partir daquele ponto de vista. Para fins de clareza, entende-se aqui pelo termo "mídia de fronteira" aqueles veículos atuantes e sediados em cidades da linha de fronteira e da faixa de fronteira. A localização geográfica é relevante. Ao estar imerso na realidade desses espaços em que a delimitação nacional não significa separação cultural absoluta entre nacionais de dois ou mais países, um veículo de comunicação se adapta às contingências e atua junto a um público diverso do que se pode esperar encontrar em outros espaços do território nacional. Além da identificação cultural, por força da legislação sobre as áreas de segurança nacional, de onde deriva o conceito administrativo e legal de faixa de fronteira, há a aproximação da estrutura administrativa. Esses veículos certamente partilham características empresariais entre si.

Além dos veículos de comunicação situados nas fronteiras, interessa também para este artigo o panorama sobre processos comunicacionais, incluindo trabalhos que abordem fatos e formações sociais, históricas e culturais que tenham lugar nesses espaços limítrofes dos territórios nacionais. O foco estaria, então, voltado para papers sobre como se estrutura o contexto fronteiriço pelo viés comunicacional, estando ou não os suportes e veículos da mídia na função de objetos de estudo.

As buscas foram feitas nos repositórios de anais de eventos das edições do Congresso Brasileiro de Ciências da Comunicação, promovido anualmente pela Sociedade Brasileira de Estudos Interdisciplinares da Comunicação (Intercom), a associação mais importante do ponto de vista de representatividade dos diversos ramos de estudo das práticas comunicacionais no Brasil, promotora de intensa e prolífica conexão com outras sociedades científicas nacionais e de outros países. O motivo da seleção é a relevância desse evento para a comunidade de pesquisadores e estudantes de Comunicação no país.

Essa escolha, feita por questões de tempo e extensão, não representa o total da produção, pois exclui da análise outros repositórios da produção científica, como os bancos de teses e dissertações de programas de pós-graduação em Comunicação e anais de eventos regionais. Mesmo com essa ressalva, se pode mensurar os fatores que conformam a presença em quantidade e qualidade das pesquisas sobre esse assunto. 
A pesquisa, por contar com buscadores internos a cada repositório, baseou-se na procura pela palavra "fronteira", que gerava a coleta de artigos submetidos que contivessem a palavra nos campos "título", "resumo" e "palavras-chave". Como o foco deste artigo é ampliar a visão sobre os trabalhos produzidos no Brasil sobre mídia e comunicação nas fronteiras, não se usou outros termos que reduzissem a pesquisa.

Como comentários breves antes de expor os resultados, deve-se apontar que a polissemia do termo "fronteira", como limiar, espaço de encontro entre diferentes, de hibridização, foi representada ao longo da busca. O autor se deparou com artigos que expunham assuntos como as bordas entre o Jornalismo e outras linguagens, o caráter desterritorializado das mídias sociais na Internet, limites entre ficção e realidade no cinema e na literatura, limiares de significações. Em resumo, trabalhos que não tratavam de mídia de fronteira ou de processos comunicacionais ou de outros âmbitos ligados a cidades fronteiriças.

A coleta permitiu uma leitura dirigida dos artigos de interesse, compondo uma fração do estado da arte sobre os estudos comunicacionais brasileiros a respeito das fronteiras. Essa foi a motivação para a ampliação do escopo para além dos trabalhos que versam sobre a mídia de fronteira do Rio Grande do Sul com a Argentina, ramo de interesse da pesquisa em andamento. Parte-se da premissa de que cada ponto de fronteira se constitui em um espaço dotado de história e estruturado em função das ações humanas, ou seja, possui especificidades. Ao mesmo tempo, as áreas limítrofes entre estados nacionais recebem os impactos das políticas nacionais e são fontes de fenômenos mais ou menos gerais, como a travessia, o comércio e a interação cultural, permitindo notar similaridades de caso a caso.

Finalmente, informa-se que nenhum artigo dentro do escopo desejado foi encontrado no download dos anais do congresso da Intercom em 2000. Porém, no arquivo compactado baixado da página do evento faltavam os artigos apresentados no GT17, o qual não se conseguiu identificar até o fechamento do artigo, motivo pelo qual este ano não participa da coleta, nem da análise exposta a seguir.

\section{RESULTADOS DA BUSCA}

A contar da edição de 2001, a representação das mídias e processos comunicacionais fronteiriços nos eventos nacionais da Intercom apresenta oscilações, com um indício de regularidade a partir de 2014. É a partir daquele ano, também, que se chega ao maior número de pesquisas voltadas para o tema, com sete trabalhos expostos em cada evento, como se nota 
na Figura 1. A criação dos colóquios Brasil-Argentina, a partir de 2008, ajudou a fomentar a exposição de artigos que, por vezes, levam os participantes a considerar o espaço fronteiriço. É importante também ressaltar que o grupo de pesquisa (doravante indicado pela sigla GP) Geografias da Comunicação, criado em 2008 junto ao Conselho Nacional de Desenvolvimento Científico e Tecnológico (CNPq) para abrigar os trabalhos nos quais a Comunicação e a Geografia se conectam nas investigações sobre as interfaces das duas áreas, começa a receber os trabalhos vinculados ao tema da fronteira a partir da $32^{\mathrm{a}}$ edição do Intercom. Antes, os artigos voltados para a temática estavam distribuídos em outros GPs conforme o suporte ou processo comunicacional que estivesse sendo estudado.

A participação dos papers sobre as fronteiras brasileiras começa tímida, mas apresenta crescimento ao longo do tempo: dois artigos em 2009, um artigo em cada edição nos anos de 2011, 2012 e 2013, e três em cada edição nos anos de 2014 e 2015. A variedade de autores também aumentou no período, em compasso com os temas de pesquisa. Há uma tendência sutil, ainda a confirmar, de formação de novos pesquisadores que se interessam pela riqueza de temas ligados à comunicação nas áreas fronteiriças.

A produção científica sobre a comunicação nas regiões fronteiriças entre o Brasil e os países vizinhos que foi levada aos principais eventos nacionais da área tem aumentado. Diferentes pontos de contato fronteiriço estão sendo estudados, ainda sem grande sistemática, mas com vivo interesse. No entanto, no período inicial há uma prevalência dos estudos sobre as fronteiras localizadas na região Sul, com maior presença dos pontos Santana do Livramento/Rivera (Uruguai) e Uruguaiana/Paso de los Libres (Argentina), seguido de perto por Foz do Iguaçu/Puerto Iguazu (Argentina)/Ciudad del Este (Paraguai). O ponto fronteiriço ${ }^{1}$ São Borja (RS)/Santo Tomé (Corrientes, Argentina) passa a figurar nos estudos comunicacionais a partir da instalação dos cursos de Jornalismo e de Publicidade e Propaganda no campus local da Universidade Federal do Pampa.

\footnotetext{
${ }^{1}$ Ao longo do artigo, serão usadas as expressões "ponto fronteiriço" e "espaço fronteiriço" como sinônimos.
} 


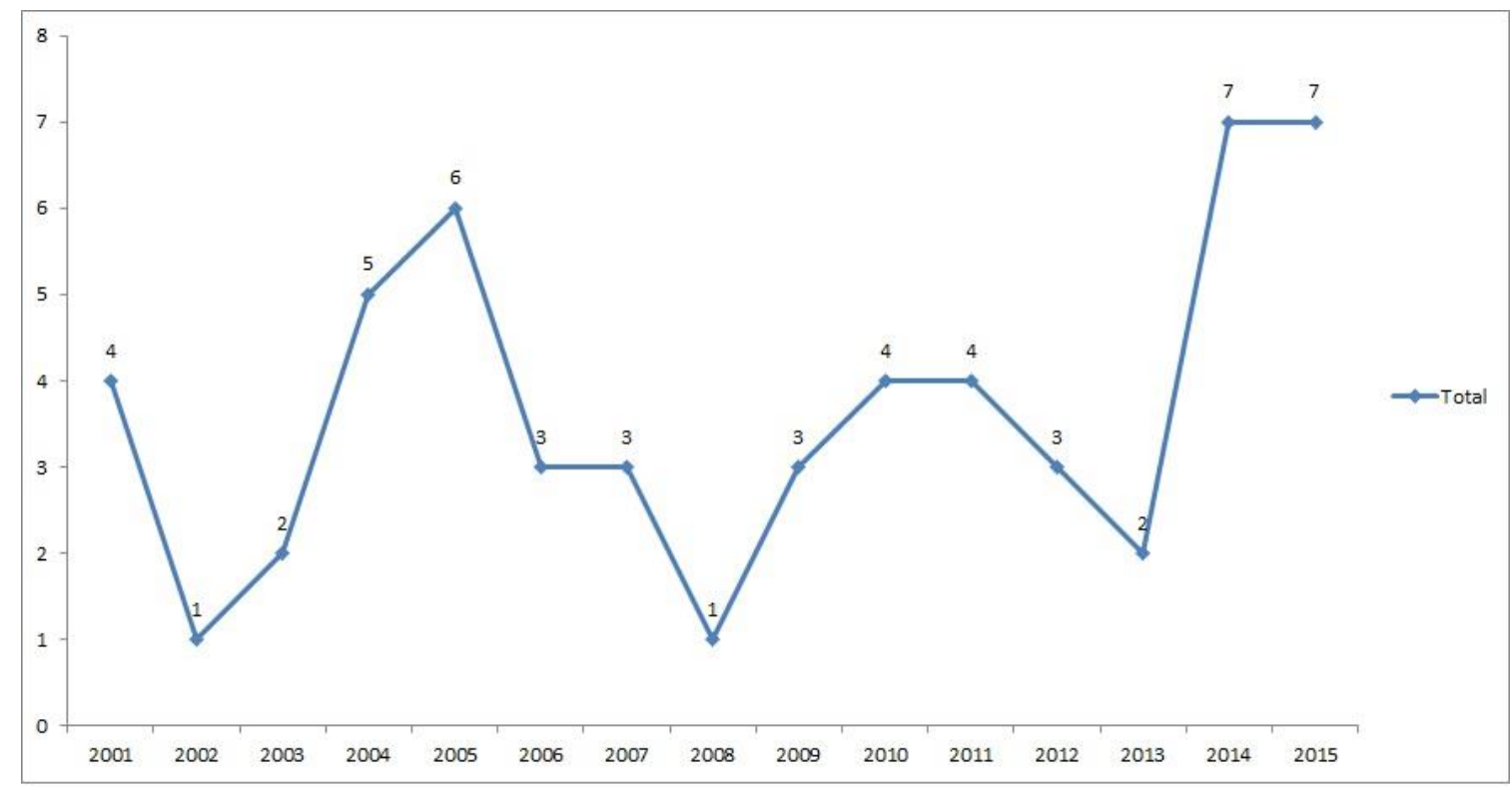

Gráfico 1 - Distribuição dos artigos por edição do Intercom Nacional (2001-2015)

Fonte: 0 autor.

A Região Sul também é a que teve seus espaços de fronteira estudados há mais tempo. Imagina-se que a densidade populacional dessa fração da linha limítrofe nacional com os demais países, com a consequente riqueza de interações entre países e povoamentos fronteiriços, incluindo dentre os resultados a identidade fronteiriça e a identidade gaúcha, fomentou mais curiosidade. O primeiro paper sobre as mídias das fronteiras da Região Centro-Oeste foi apresentado em 2004, pela professora Daniela Ota. As fronteiras da Região Norte só foram aparecer em dois artigos apresentados no Intercom de 2014, a partir de análise da professora Ada Cristina Machado Silveira sobre como duas produções noticiosas desenvolvidas para a televisão expõem o espaço fronteiriço de Tabatinga, no estado do Amazonas, como fragilmente protegido e disponível para o crime. 


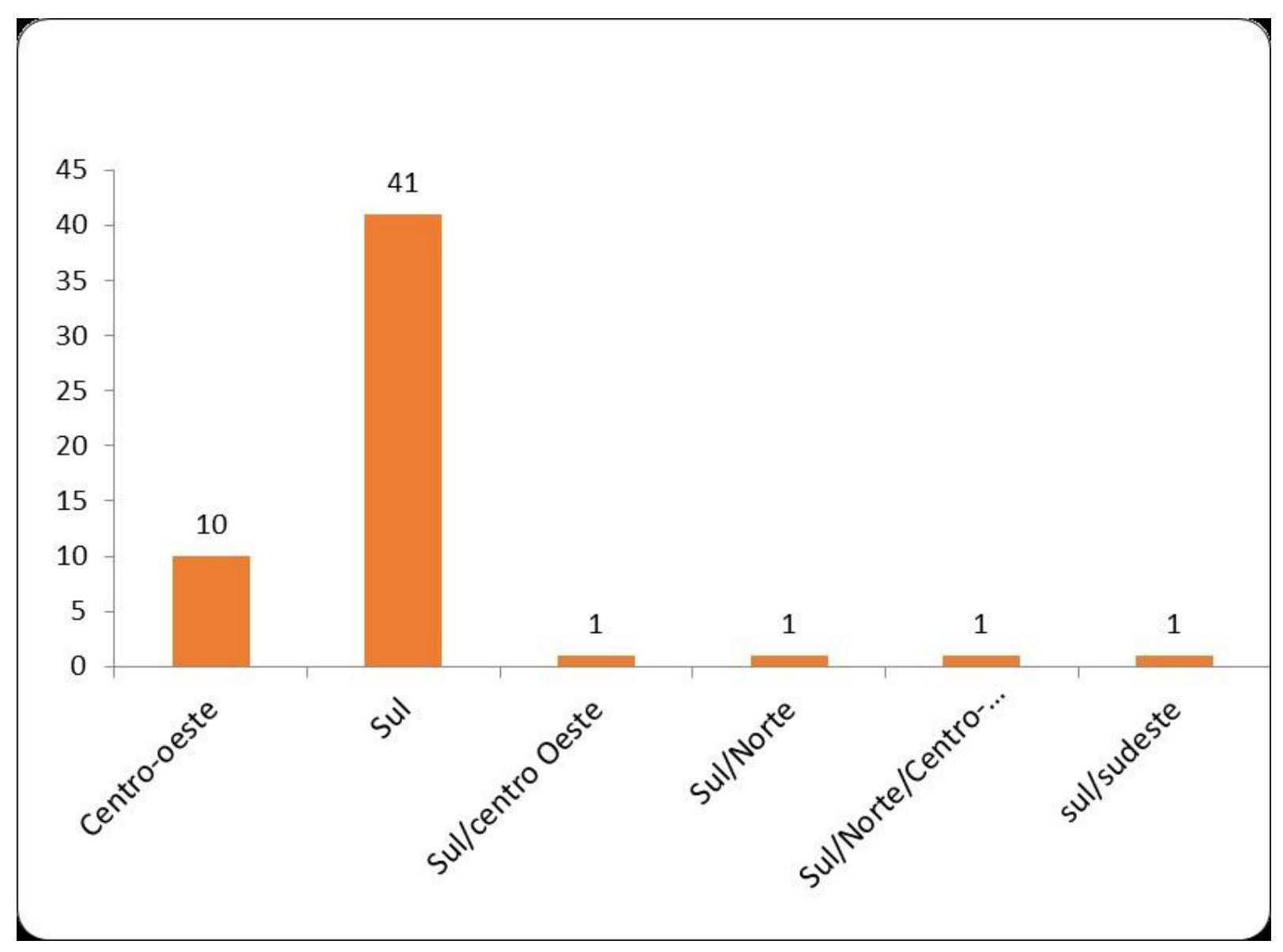

Gráfico 2 - Distribuição de artigos por região estudada (2001-2015)

Fonte: o autor

\subsection{Autoras e preocupações de pesquisa}

É justo destacar que o olhar sobre as fronteiras brasileiras, suas mídias e seus ecossistemas comunicacionais é predominantemente feminino, ao menos em relação aos eventos nacionais da Intercom e no período abordado neste artigo. As professoras Ada Cristina Machado da Silveira (UFSM), Karla Maria Müller (UFRGS), Roberta Brandalise (Faculdade Cásper Líbero) e Daniela Cristiane Ota (UFMS) são as presenças mais constantes no levantamento realizado por este autor. Sem desmerecer os autores do gênero masculino, esse predomínio talvez possa ser explicado em um estudo de outro tipo que não o presente neste artigo. $\mathrm{O}$ trabalho realizado até o momento é bastante rico em visadas, alternando do contexto ao caso; a riqueza também inclui as metodologias, evidenciando as táticas usadas para dar conta das várias articulações em tudo o que envolve a comunicação na fronteira. Em grande parte, esse tema está presente por conta dos esforços dessas pesquisadoras. 
O trabalho conduzido pela professora Ada Cristina Machado da Silveira, docente da Universidade Federal de Santa Maria (UFSM), regularmente implica novos pesquisadores em investigações sobre diferentes aspectos do fenômeno fronteira, e gerou 11 papers sobre o tema nos eventos nacionais da Intercom entre 2001 e 2015, em regime de autoria e co-autoria. É especialmente relevante o conceito de "terras de fronteira do Brasil Meridional", por ela desenvolvido, por trazer um olhar que articula a história da formação e ocupação do Rio Grande do Sul à criação do que chama de "malha de comunicação", o conjunto de veículos de comunicação e as diferentes características que as empresas, tanto locais quanto sucursais de redes, conferem aos fluxos de informação. Os trabalhos de contextualização das terras de fronteira (SILVEIRA, 2001; 2003; 2005) ajudam a situar temporal e espacialmente fenômenos como a circulação de programação televisiva massiva e nacional em uma região de encontro entre diferentes nações, a tendência entre os jornais impressos de assumir uma visão globalizada e a prática das emissoras de rádio de envergar o localismo e a territorialidade como diferenciais junto ao público.

A partir do desenvolvimento consistente de sua percepção sobre como a comunicação a respeito das áreas fronteiriças reforça a condição de periferia para além dos indicadores geográficos, Silveira expandiu as investigações para entender os diferentes pontos de vista sobre o tema em locais e suportes midiáticos distintos: dos jornais impressos à web e, mais recentemente, sobre as produções telejornalísticas (SILVEIRA, 2006; SILVEIRA, BARLETE et al., 2007; SIMI, SILVEIRA, 2010; SILVEIRA, 2011; 2014a; 2014b). Dentre suas preocupações estão as construções discursivas geradas pelos meios hegemônicos, pela imprensa de referência, sobre os espaços limítrofes do Brasil com outros países, e como essas falas contribuem para situações como a influência na cobertura dos jornais locais, a repetição dos vieses negativos nas notícias sobre as fronteiras a partir da televisão e o reforço ao preconceito e à invisibilidade sobre a complexidade desses ambientes sociais.

Suas investigações podem ser conectadas, neste sentido, às indagações feitas por Castells (2009, p. 376) sobre o influxo da política midiática com o intento de moldar a mente do público. Caberiam aí as perguntas: a quem interessam as questões de fronteira, para que sejam tão desconsideradas? A que propósitos servem os constantes esforços de "recapagem estereotípica" em relação aos povos vizinhos e aos espaços fronteiriços? Em que medida essa situação serve à política, às empresas de comunicação e ao empresariado em geral?

Com especial atenção para o impacto das redes estaduais e nacionais de televisão sobre o cotidiano fronteiriço, a pesquisadora Roberta Brandalise (Cásper Líbero) desenvolveu 
uma dissertação e uma tese sobre o tema. Seus nove artigos evidenciam dois jogos que estão relacionados de forma assimétrica. Agindo massivamente sobre o território nacional, a Rede Globo produz noticiário e dramaturgia plenos de estereotipias e discursos sobre as memórias sobre os povoamentos e costumes dos limites do Brasil com a Argentina e o Uruguai e sobre os povos "do lado de lá" das linhas do território pátrio, por meio de telenovelas, transmissões e comentários de jogos de futebol e reportagens (BRANDALISE 2002; 2005; 2006; 2009; 2012a; 2012b; 2014; 2015a; 2015b). No segundo plano, o da recepção e circulação dos sentidos, esses estereótipos positivos e negativos simplificam o entendimento sobre as relações entre o país e seus vizinhos e muitas vezes prejudicam a sociabilidade típica da fronteira sul.

O crime, o futebol, a publicidade e a política internacional são os assuntos mais influentes nos prejuízos, enquanto que alguns produtos televisivos como a reportagem e as séries e novelas abrem espaço para a descrição positiva das diferenças. Assim, expõe Brandalise, a produção televisiva da Rede Globo mais fomenta a tensão e o reforço das identidades nacionais que o entendimento e a troca, funções que Silveira (2003) já havia identificado como conectadas à territorialidade do rádio e que Raddatz (2005) descreve a respeito do rádio de fronteira, como ator que recebe elementos culturais do ambiente hibrido e a ele devolve com a programação noticiosa e musical.

A pesquisadora Karla Müller, em suas investigações sobre as identidades fronteiriças e como essas definições dinâmicas influem e são retrabalhadas pela imprensa local dos espaços "Uruguaiana-Paso de Los Libres" e "Santana do Livramento-Rivera", indicou fenômenos que foram corroborados depois por outros estudos, entre eles os de Silveira e de Ota. Um deles é a diferença de abordagens sobre os temas conexos à travessia dos limiares nacionais entre as fronteiras conurbadas (em que as cidades gêmeas constituem um único complexo urbano) e as semi-conurbadas (nas quais os centros urbanos estão separados, mas ainda assim bastante próximos). A presença de diferentes etnias, como a árabe-palestina, é também abordada do ponto de vista da integração nos fluxos comunicacionais dessas cidades (MÜLLER, 2004). As experiências com conteúdo bilíngue nos veículos de comunicação fronteiriços, buscando atrair o leitor e o ouvinte de língua espanhola, também aparecem nos trabalhos (MÜLLER, 2008) como mescla de estratégia comercial e ação no ambiente de mestiçagem linguística. Ao longo do período 2001-2015 dos eventos nacionais da Intercom, a pesquisadora é autora de quatro artigos e co-autora em outros dois. 
Müller também pesquisou a construção discursiva de jornais metropolitanos sobre o turista argentino no litoral sul-brasileiro no começo dos anos 2000 (JACKS; MÜLLER; MACHADO, 2001), constatando a influência dos processos de estereotipia na construção dos relatos sobre a vinda dos hermanos e as dificuldades de integração. Essa contribuição forma um contraponto básico para notar o quanto a diferença de espaços, no sentido certeauniano do termo, conforma a percepção sobre o outro, o estrangeiro.

A presença de estudos sobre a mídia de fronteira da Região Centro-Oeste deve ser creditada aos pesquisadores da Universidade Federal do Mato Grosso do Sul (UFMS), dentre os quais a professora Daniela Ota é uma das presenças mais constantes nas edições nacionais, com cinco artigos no período estudado, entre papers de sua autoria exclusiva e em regime de co-autoria. A grande ênfase da participação dos pesquisadores da UFMS é a presença e a atuação das emissoras de rádio na região fronteiriça do estado do Mato Grosso do Sul, embora outros meios de comunicação sejam também abordados. Dentre suas contribuições estão a recuperação histórica da formação das fronteiras do estado (OTA, 2009), e o mapeamento da mídia sul-matogrossense (OTA, 2011), que vai ser aprimorado em trabalho posterior (RODRIGUES FILHO, OTA, 2013).

\section{CONSIDERAÇÕES PROVISÓRIAS}

O levantamento realizado permite avançar algumas considerações a respeito de como o fenômeno fronteira foi abordado do ponto de vista da comunicação. O primeiro ponto diz respeito a um entendimento bastante verificado nos artigos: a caracterização da fronteira supera o caráter político-administrativo das demarcações e avança, em geral, para o entendimento de que essas áreas são, a um mesmo tempo, delimitações de poder a partir dos estados-nação vizinhos, zonas de comércio, convivência e mescla cultural, áreas de tensão entre a identidade nacional e a identidade fronteiriça, locais onde a sociabilidade flutua entre a aproximação e o afastamento pela própria conformação dos povoamentos e também de acordo com as notícias, a publicidade e outros temas de interesse comum. Essa noção de complexidade da fronteira é fundada nos trabalhos de pesquisadores de campos distintos, como Jesús Martín-Barbero, Nestor García Canclini, Michel de Certeau, Milton Santos e Stuart Hall, as fontes mais presentes nos artigos analisados.

Essa visão, muito mais rica que a mirada limitada às bordas do poder administrativo nacional, favorece a conexão com a proposta da economista e socióloga Saskia Sassen (2007) 
de "desligar" a noção de fronteira das circunscrições nacionais para entender as lógicas operativas de grandes empresas transnacionais, gerando uma acepção adicional para o termo. Trata-se de indagar se não estamos rumo a um mundo dotado de um sistema legal global, desconectado do conceito de estado-nação que funda o direito internacional.

Esse processo, explica Sassen, "assinala um deslocamento da autoridade do setor público rumo ao setor privado em matéria de governo da economia global" (2007, p. 279), levando à instalação de novos "espaços e regimes com novas demarcações fronteiriças" (2007, p. 280) por meio das transnacionais, aptas a operar em um espaço físico e no ambiente digital, dentro das fronteiras nacionais. Esse movimento faz com que se indague sobre o novo papel das áreas fronteiriças nacionais, além de perímetro protetivo. A conjunção de limiares entre o material e o digital, o público e o privado e os territórios nacionais tensionam também a noção de contexto, convencionalmente ligada ao espaço físico local, enquanto Sassen propõe a ampliação do conceito para dar conta das redes de subeconomias (as empresas transnacionais e suas expansões no mundo) que são também globais e digitais.

A discussão parece proveitosa também para estudos em comunicação: fenômenos como a multiplicação de modelos de entrega de conteúdo (vídeo, áudio, livros, jogos, notícias...) pela Internet, além de afetar as empresas de mídia tradicional (que precisavam de altos custos para levar suas produções ao longo do território), também fomenta delimitações, e também pontos de encontros, no acesso e consumo de conteúdo. Nas áreas fronteiriças, que já respondem aos processos midiáticos convencionais e estão, aos poucos, sendo permeadas também pela infraestrutura de acesso à Internet, essa inovação também deve gerar efeitos dignos de estudo, como, por exemplo, as apropriações de serviços de rede social para a circulação de notícias, promoção de eventos e mesmo os debates sobre acontecimentos, ou para circular outras apropriações de ainda outros conteúdos.

Sassen menciona que essa diferenciação entre digital e social depende de culturas e práticas mediadoras, conformadas por sua vez em função de sistemas de poder, culturas, sistemas de valores e ordens institucionais (2007, p. 293). Retorna-se ao relacionamento com a mídia, conectando-se a mediação com o novo contexto, ligando o global e o local em rede por meio da Internet e fazendo deles elementos multiescalares (2007, p. 298).

É por meio dessa discussão trazida por Sassen que se chega à segunda consideração do artigo: ainda se pesquisa pouco sobre como as mediações digitais estão ocorrendo nas áreas de fronteira. No período analisado, nenhum artigo trouxe dados de pesquisa aprofundada nas 
questões que podem surgir dessa ligação das fronteiras com o "mundo sem fronteiras" da Web.

O aspecto da conexão global aventado pelos serviços de comunicação via Internet parece ser a um turno o potencial inexplorado e o óbice para mais investigações sobre o que o fronteiriço fala de sua fronteira, como a descreve nas redes sociais, que aspectos de sua vivência transparecem nas suas marcas digitais. Outros fatores que parecem explicar o fato são o lento avanço da infraestrutura de acesso nessas regiões, o histórico recente da abertura da Internet comercial no Brasil, em 1995, as condições socioeconômicas das cidades fronteiriças em geral e o predomínio, ainda que decadente, das redes nacionais e regionais de comunicação.

Consumo de notícias, análise de sentimentos nas redes sociais, apropriações de ferramentas e conteúdos, infraestrutura de acesso nessas regiões, a vivência e a significação da fronteira conectada em rede e outras indagações ainda estão por serem sistematizadas por pesquisadores da Comunicação.

Finalmente, o aspecto do período temporal estudado na maioria dos artigos ressalta a busca da compreensão de como as identidades e as interações se mostram na contemporaneidade. Com exceção dos artigos sobre terras de fronteira de Ada Cristina Machado da Silveira, e de um artigo sobre a formação histórica das cidades fronteiriças de Mato Grosso do Sul, por Daniela Ota, os olhares dos pesquisadores estiveram voltados para processos, produtos e acontecimento atuais.

A baixa contagem de papers com teor histórico na amostra analisada provavelmente se deve à possibilidade de se dirigir estudos com esse viés para as edições do Encontro Nacional da História da Mídia (Alcar). Artigo recente sobre mídia de fronteira na Região Sul confirma essa preferência (NAZÁRIO, 2015a), com variedade de análises a partir de fatos comunicacionais e períodos históricos. No entanto, com base nas observações feitas sobre fenômenos recentes, é possível investir em estudos longitudinais, que abranjam períodos mais extensos e afastados na duração do tempo. Parece interessante também explorar o noticiário fronteiriço de épocas mais afastadas para estabelecer uma ponte entre os estudos de fronteira e as investigações no ramo do jornalismo internacional, ou com a hipótese do Newsmaking. $\mathrm{O}$ caso do noticiário sobre a Guerra das Malvinas em dois jornais interioranos, um de São Borja e outro de Santo Tomé (NAZÁRIO, 2015b), é uma tentativa de entender como os jornais trabalhavam para equilibrar os temas de proximidade geográfica e cultural em uma 
espacialidade complexa considerações devem apresentar o fechamento do trabalho, abordando as questões de pesquisa correspondentes aos objetivos propostos.

\section{REFERÊNCIAS}

BRANDALISE, Roberta. Gaúchos e gauchos: um pampa, duas nações. In: XXXVIII Congresso Brasileiro de Ciências da Comunicação, 2002, Salvador - BA. Anais 2002. São Paulo: Intercom, 2002.

Ficção e realidade às margens do Rio Uruguai: Um olhar fronteiriço sobre A Casa das Sete Mulheres. In: XXVIII Congresso Brasileiro de Ciências da Comunicação, 2005, Rio de Janeiro - RJ. Anais 2005. São Paulo: Intercom, 2005.

. Comunicação e diversidade cultural na fronteira Brasil-Argentina. In:

XXIX Congresso Brasileiro de Ciências da Comunicação, 2006, Brasília - DF. Anais 2006. São Paulo: Intercom, 2006.

Diversidade cultural e apropriação de bens simbólicos na fronteira BrasilArgentina. In: XXXII Congresso Brasileiro de Ciências da Comunicação, 2009, Curitiba - PR. Anais 2009. São Paulo: Intercom, 2009.

Futebol e Rivalidade na Fronteira Brasil-Argentina: Pelé e Maradona na Televisão Brasileira. In: XXXV Congresso Brasileiro de Ciências da Comunicação, 2012, Fortaleza CE. Anais 2012. São Paulo: Intercom, 2012.

Futebol, Memória e o Estereótipo da "Fronteira da Paz": Brasileiros, Uruguaios e a Final Copa de 50 na Televisão Brasileira. In: XXXV Congresso Brasileiro de Ciências da Comunicação, 2012, Fortaleza- CE. Anais 2012. São Paulo: Intercom, 2012.

Televisão brasileira nas fronteiras paraguaio-brasileira, argentino-brasileira e uruguaio-brasileira: identidade e diferença, aproximação e distanciamento ou colaboração e conflito entre povos. In: XXXVII Congresso Brasileiro de Ciências da Comunicação, 2014, Foz do Iguaçu PR. Anais 2014. São Paulo: Intercom, 2014.

A representação positiva do Uruguai e a reafirmação do estereótipo da amizade uruguaio-brasileira no telejornalismo e no imaginário fronteiriço. In: XXXVIII Congresso Brasileiro de Ciências da Comunicação, 2015, Rio de Janeiro - RJ. Anais 2015. São Paulo: Intercom, 2015.

As relações interculturais da fronteira Argentina-Brasil mediadas pelo consumo da televisão brasileira. In: XXXVIII Congresso Brasileiro de Ciências da Comunicação, 2015, Rio de Janeiro - RJ. Anais 2015. São Paulo: Intercom, 2015.

CASTELLS, Manuel. Comunicación y Poder. Madrid, Alianza, 2009.

JACKS, Nilda; MÜLLER, Karla; MACHADO, Márcia Benetti. Os argentinos “invadem” o Brasil: a representação dos "hermanos" no discurso jornalístico sulino. In: XXIV Congresso Brasileiro de Ciências da Comunicação, 2001, Campo Grande - MS. Anais 2001. São Paulo: Intercom, 2001. 
LOPES, Gregório; SILVEIRA, Ada Cristina Machado. O Estranho na Tríplice Fronteira: a delimitação, a vigília e o expurgo. In: XXXIII Congresso Brasileiro de Ciências da Comunicação, 2010, Caxias do Sul - RS. Anais 2010. São Paulo: Intercom, 2010.

MOURA E SILVA, João Victor Borba; SILVEIRA, Ada Cristina Machado. O Enquadramento Jornalístico sobre a Tríplice Fronteira. In: XXXIII Congresso Brasileiro de Ciências da Comunicação, 2010, Caxias do Sul - RS. Anais 2010. São Paulo: Intercom, 2010.

MÜLLER, Karla Maria. Cenários para pensar a comunicação fronteiriça: Uruguaiana-Libres e Livramento-Rivera. In: XXIV Congresso Brasileiro de Ciências da Comunicação, 2001, Campo Grande - MS. Anais 2001. São Paulo: Intercom, 2001.

Entrelaçamentos entre mídia local, identidade e cultura fronteiriça. In: XXVI Congresso Brasileiro de Ciências da Comunicação, 2003, Belo Horizonte - MG. Anais 2003. São Paulo: Intercom, 2003.

Inserções de Árabes-Palestinos na Fronteira e na mídia impressa local. In: XXVII Congresso Brasileiro de Ciências da Comunicação, 2004, Porto Alegre - RS. Anais 2004. São Paulo: Intercom, 2004.

Identificação de elementos da cultura e da identidade apresentados pela mídia impressa na região de fronteira. In: XXVIII Congresso Brasileiro de Ciências da Comunicação, 2005, Rio de Janeiro - RJ. Anais 2005. São Paulo: Intercom, 2005.

; RADDATZ, Vera Lúcia Spacil. Relações socioculturais na linguagem da mídia de fronteira: Ponta Porã/Brasil-Pedro Juan Caballero/Paraguai. In: XXXI Congresso Brasileiro de Ciências da Comunicação, 2008, Natal - RN. Anais 2008. São Paulo: Intercom, 2008.

NAZÁRIO, Heleno Rocha. Caracterização de estudos sobre mídia de fronteira Brasil e Argentina nos Encontros Nacional de História da Mídia. In: Encontro Nacional de História da Mídia, 2015b, Porto Alegre - RS. Anais do $10^{\circ}$ Encontro Nacional de História da Mídia, 2015. Disponível em < http://www.ufrgs.br/alcar/encontros-nacionais-1/encontros-nacionais/10o-encontro-2015/gt-historiado-jornalismo/caracterizacao-de-estudos-sobre-midia-de-fronteira-brasil-e-argentina-nos-encontrosnacional-de-historia-da-midia/at_download/file>

; HAUSSEN, D. F. . Guerra das Malvinas (1982) nos jornais fronteiriços Folha de São Borja (Brasil) e Unión (Argentina). In: XXXVIII Congresso Brasileiro de Ciências da Comunicação, 2015b, Rio de Janeiro - RJ. Anais 2015. São Paulo: Intercom, 2015.

OTA, Daniela Cristiane; LINHARES, Gladis. Jornalismo local nas fronteiras do Brasil, Paraguai e Bolívia. In: XXVII Congresso Brasileiro de Ciências da Comunicação, 2004, Porto Alegre - RS. Anais 2004. São Paulo: Intercom, 2004.

Representação histórica das cidades fronteiriças de Mato Grosso do Sul. In: XXVII Congresso Brasileiro de Ciências da Comunicação, 2009, Curitiba - PR. Anais 2009. São Paulo: Intercom, 2009.

Mapeamento da mídia fronteiriça em Mato Grosso do Sul. In: XXXIV Congresso Brasileiro de Ciências da Comunicação, 2011, Recife - PE. Anais 2011. São Paulo: Intercom, 2011.

; RODRIGUES FILHO, Lairtes Chaves. Geografias da Comunicação na pesquisa sul-mato-grossense: fronteiras, territórios e perspectivas. In: XXXVI Congresso Brasileiro de Ciências da Comunicação, 2013, Manaus - AM. Anais 2013. São Paulo: Intercom, 2013. 
PIPPI, Joseline. Ciência \& Tecnologia na Imprensa de Fronteira do RS: Reflexões sobre Discurso Noticioso e Singularidades Produtivas. In: XXXVIII Congresso Brasileiro de Ciências da Comunicação, 2015, Rio de Janeiro - RJ. Anais 2015. São Paulo: Intercom, 2015.

RADDATZ, Vera Lúcia Spacil. Identidade cultural e comunicação de fronteira. In: XXVII Congresso Brasileiro de Ciências da Comunicação, 2004, Porto Alegre - RS. Anais 2004. São Paulo: Intercom, 2004.

As Representações da Identidade Cultural no Rádio de Fronteira. In: XXVIII Congresso Brasileiro de Ciências da Comunicação, 2005, Rio de Janeiro - RJ. Anais 2005. São Paulo: Intercom, 2005.

Rádio de fronteira na web: um espaço para as práticas culturais. In: XXX Congresso Brasileiro de Ciências da Comunicação, 2007, Santos - SP. Anais 2007. São Paulo: Intercom, 2007.

Produção cultural na mídia fronteiriça Brasil-Argentina. In: XXXIV Congresso Brasileiro de Ciências da Comunicação, 2011, Recife - PE. Anais 2011. São Paulo: Intercom, 2011.

RODRIGUES FILHO, Lairtes Chaves. Webrádios, streaming e migração de banda: tendências para as linguagens digitais nas rádios da fronteira Brasil-Paraguai. In: XXXVII Congresso Brasileiro de Ciências da Comunicação, 2014. Foz do Iguaçu - PR. Anais 2014. São Paulo: Intercom, 2014.

; SILVA, Mayara Martins da Quinta Alves da; OTA, Daniela Cristiane. Elementos da legislação de radiodifusão comparada Brasil-Paraguai e a organização da comunicação no espaço cultural de fronteira. In: XXXVIII Congresso Brasileiro de Ciências da Comunicação, 2015, Rio de Janeiro - RJ. Anais 2015. São Paulo: Intercom, 2015.

SASSEN, Saskia. Una Sociología de la Globalización. Buenos Aries: Katz, 2007.

SIMI, Gianlucca; SILVEIRA, Ada Cristina Machado. O Enquadramento Jornalístico sobre a Tríplice Fronteira. In: XXXIII Congresso Brasileiro de Ciências da Comunicação, 2010, Caxias do Sul - RS. Anais 2010. São Paulo: Intercom, 2010.

SILVEIRA, Ada Cristina Machado. Terras de Fronteira: a variedade das estratégias de comunicação no Brasil Meridional. In: XXIV Congresso Brasileiro de Ciências da Comunicação, 2001, Campos Grande - MS. Anais 2001. São Paulo: Intercom, 2001.

A malha de comunicação local-internacional do Brasil Meridional. In: XXVI Congresso Brasileiro de Ciências da Comunicação, 2003, Belo Horizonte - MG. Anais 2003. São Paulo: Intercom, 2003.

Fronteiras da globalização: polifonia, identidade, estado-nação. In: XXVIII Congresso Brasileiro de Ciências da Comunicação, 2005, Rio de Janeiro - RJ. Anais 2005. São Paulo: Intercom, 2005.

Comunicação e Estado: Nação e fronteiras do desencontro. In: XXIX Congresso Brasileiro de Ciências da Comunicação, 2006, Brasília - DF. Anais 2006. São Paulo: Intercom, 2006. 
XXX Congresso Brasileiro de Ciências da Comunicação, 2007, Santos - SP. Anais 2007. São Paulo: Intercom, 2007.

Problematizando a política de identidade: narrativas securitárias e imunização contra a diferença. In: XXXIV Congresso Brasileiro de Ciências da Comunicação, 2011 Recife - PE. Anais 2011. São Paulo: Intercom, 2011.

O nome do outro. Heterotopias e interações fronteiriças. In: XXXVII

Congresso Brasileiro de Ciências da Comunicação, 2014. Foz do Iguaçu - PR. Anais 2014. São Paulo: Intercom, 2014.

A Espacialidade na cobertura jornalística: Mapas e percursos nas fronteiras nacionais. In: XXXVII Congresso Brasileiro de Ciências da Comunicação, 2014. Foz do Iguaçu - PR. Anais 2014. São Paulo: Intercom, 2014.

Original recebido em: 04 de maio de 2016

Aceito para publicação em: 30 de março de 2017

Beatriz Corrêa Pires Dornelles

Pesquisadora e Professora $\mathrm{Dr}^{\mathrm{a}}$ no PPGCom da Faculdade de Comunicação Social (Famecos) da Pontifícia Universidade Católica do Rio Grande do Sul (PUCRS)

Heleno Rocha Nazário

Jornalista, Mestre em Comunicação Social pelo PPGCom da Faculdade de Comunicação Social (Famecos) da Pontifícia Universidade Católica do Rio Grande do Sul (PUCRS)

Esta obra está licenciada sob uma Licença Creative Commons. 